\title{
A PRÁTICA DE ENFERMAGEM PSIQUIÁTRICA NO CEARÁ E SUA RELAÇÃO COM O CONTEXTO SÓCIO-HISTÓRICO*
}

\author{
Maria Nazaré de Oliveira Fraga'
}

\begin{abstract}
RESUMO: Pesquisa que utiliza a história como elemento elucidativo e interpretativo da prática de enfermagem psiquiátrica no Ceará. Utiliza de visitas, entrevistas, consultas a arquivos de instituições e jornais, e levantamento de literatura sobre a história da enfermagem e da assistência psiquiátrica na região. Constatou-se que, mesmo tendo havido alguns avanço em décadas anteriores, ainda na década de 90 , a prática de enfermagem psiquiátrica não sofreu transformações significativas: é essencialmente hospitalare embasa-se na aplicação, pelas atendentes de enfermagem, de psicotrópicos prescritos pelos psiquiatras, sob a supervisão das enfermeiras. A interação dessa prática com a assistência psiquiátrica e com a.sociedade cearense confere-lhe especificidades só compreensíveis se consideradas no conjunto, e não isoladamente.
\end{abstract}

UNITERMOS: Enfermagem Psiquiátrica - Saúde mental - História da enfermagem.

\section{INTRODUÇÃO}

Experiência docente de mais de 15 anos feznos constatar que os entraves do ensino de enfermagem psiquiátrica e suas possiveis soluções guardam relação com a totalidade da prática de enfermagem psiquiátrica e com as políticas de saúde no país. Os Encontros de Enfermeiros Psiquiátricos do Ceará ${ }^{2}$, envolvendo profissionais de ensino e de serviço, proporcionaram oportunidade para compreender que as questões e dificuldades vivenciadas pelos que atuavam na área, tinham determinações que extrapolavam aspectos, como qualificação e responsabilidade das enfermeiras, quantidade de pessoal auxiliar de enfermagem ou questões administrativas. Pesquisa realizada em $1985^{(3)}$ revelou, entre as enfermeirasque trabalhavam em psiquiatria, uma situação de ausência de qualificação para trabaIhar na especialidade, sendo o acesso a ela motivado principalmente pelo fato de ter sido a primeira oportunidade de emprego surgida, havendo ainda a pretensão de mudar de campo de trabalho. Tais achados, que mostraram um certo grau de insatisfação das enfermeiras com o trabalho da psiquiatria, não eram suficientes para explicitar as relações dessa prática como a formação social inclusiva e isso apontava a necessidade de realizar novas pesquisas.

A prática de enfermagem psiquiátrica, enquanto se realiza, reflete um conjunto de determinações históricas que se esboçam no modo como o serviço é prestado. O presente estudo orienta-se por este pressuposto e tem como objetivos: 1) resgatar os antecedentes históricos da prática de enfermagem psiquiátrica no Ceará; 2) apreender como tal prática se articula com a psiquiatria e com a saúde, e como estas se articulam com o modo de produção onde se inserem.

A presente investigação segue a trilha de várias outras já realizadas no Brasil que, processando uma macro-análise da enfermagem, têm contribuído para compreendê-la enquanto uma prática social e historicamente determinada. $(1,7,14,18,21)$. Sua realização no Ceará, entre outras causas, prende-se ao entendimento de que é necessário centrar esforços para desvendar a

\footnotetext{
Trabalho apresentado como Tema Livre no $45^{\circ}$ Congresso Brasileiro de Enfermagem. Olinda-Recife, 28 de novembro a 3 de dezembro de 1993.

1 Enfermeira, Professora Adjunta do Departamento de Enfermagem da Universidade Federal do Ceará.

2 Foram realizados em Fortaleza nos anos 1983, 1985 e 1987 com o apoio da Associaçáo Brasileira de Enfermagem - Seçáo Ceará.
} 
realidade de segmentos específicos da enfermagem, como é o caso da enfermagem psiquiátrica, e de regiões que não foram contempladas em investigações anteriores.

\section{TRILHA METODOLÓGICA}

O presente trabalho compõe parte dos resultados de uma pesquisa mais ampla e que deu origem a uma tese de doutoramento(4). É um estudo histórico-estrutural, e como tal, privilegia a história como elemento elucidativo e interpretativo da realidade estudada.

A coleta de informações foi realizada procedendo-se à associação de vários procedimentos e técnicas: realização de visitas às várias instituições prestadoras de assistência psiquiátrica para coletar dados sobre número de leitos e de trabalhadores, jornada semanal de trabalho, tipo de clientela e de assistência; consulta aos arquivos das instituições; realização de entrevistas com enfermeiras, técnicos de enfermagem, auxiliares de enfermageme atendentes; consulta aos principais jornais em circulação no Ceará3; revisão da literatura sobre a história e a assistência psiquiátrica na região 4 .

Na sequência do trabalho há uma breve referência à história econômica e política do Ceará e à assistência em saúde ali realizada, desde a colonização até recentemente. Introduzem-se elementos sobre o modo de institucionalização da prática de enfermagem psiquiátrica no território cearense e sobre as condições atuais da assistência psiquiátrica e da prática de enfermagem na especialidade, tendo como referência as instituições onde ocorrem, as categorias profissionais que trabalham no setor, as características do mercado de trabalho, entre outros.

\section{AASSISTÊNCIAPSIQUIÁTRICA NO CEARÁ}

\subsection{O Ceará e sua Economia}

A história política do que hoje constitui o Ceará, iniciou-se em 1603 com a tentativa de colonização realizada por Pero Coelho de Sousa. Incrustado na parte mais árida da Região Nordeste, ao longo de sua história, o Ceará foi explorado por portugueses, franceses e holandeses, compôs parte das capitanias de Pernambuco e da Paraíba, foi capitania autônoma sem ser sequer visitado pelo donatário, até chegar à condição atual de estado da federação.

Só quando o mercado externo, pressionado pela escassez provocada pela Guerra de Secessão norte-americana (1861), interessa-se pelo algodão de fibra longa e de melhor qualidade produzido no Ceará, é que o estado desponta na economia nordestina. A partir daí, Fortaleza começa a emergir como um grande centro urbano, inicialmente coletando e exportando a produção vinda do interior, e posteriormente, concentrando o maior polo industrial, o maior montante de empregos públicos e reunindo o maior número de instituições de educação e saúde e as mais numerosas e melhores opções de lazer.

Sem infra-estrutura capaz de absorver os que chegam fugindo das secas freqüentes, e por outras razões, Fortaleza tem seu espaço ocupado desordenadamente, apresentando disparidades, como bairros de classe média alta residente em grandes mansões, rodeados por bolsões de pobreza, cujos habitantes se amontoam em favelas sem as mínimas condições de higiene e saneamento.

As freqüentes secas, o êxodo rural crescente e a ausência de políticas de fixação do homem ao campo, fazem de Fortaleza uma cidade com mercadode trabalho muito competitivo, especialmente para os trabalhadores sem qualificação profissional, mas que não oferece condições de vida satisfatórias para a maioria de seus habitantes, nem uma assistência psiquiátrica de boa qualidade, como se verá mais adiante.

\subsection{Assistência à Saúde, Surgimento da Enfermagem e da Enfermagem Psiquiátrica}

Os índios que antigamente habitavam o Ceará tinham seus problemas de saúde tratados pelos pajés que, conhecedores das virtudes terapêuticas da flora nativa, utilizavam-na em associação com procedimentos mágicos e sangrias. A constatação, por parte dos colonizadores, de que as raizes, folhas e cascas eram adequadas às moléstias tratadas, motivou desde o comércio

\footnotetext{
3 A consulta abrangeu a década de 80 e início da década de 90 e prendeu-se aos Jornais "O Povo", Diário do Nordeste", e "Tribuna do Ceará".

4 Tendo em vista as características do estudo, o tópico Revisåo de Literatura é apresentado ao longo do corpo do trabalho.
} 
inescrupuloso por parte de leigos, até a busca orientada e posterior estudo e aplicação de plantas medicinais do Ceará por parte de pesquisadores da Universidade de Coimbra ${ }^{(12)}$.

A primeira referência encontrada sobre os precursores, no Ceará, do que mais tarde viria a constituir a prática de enfermagem, está relacionada à grande expedição dos portugueses para expulsão dos franceses da capitania do Maranhão e revela que

"na frota de cinco caravelóes e dois patachos que tocou o Mucuripe e que daí se dirigiu ao Maranhăo, sob o comando de Diogo de Campos, a célebre Armada Milagrosa de 1614, viajava uma enfermeira, a mulher do pardo Joáo Neto, certamente a pioneira da profissåo por estas bandas". (Rocha apud LEAL ${ }^{12,}$ p.22) Há poucos dados sobre as instituições que dispensavam assistência à saúde da população do Ceará durante sua colonização. Certamente os jesuítas foram alguns dos pioneiros na prestação de assistência à saúde ali, como em outras regiões do país, pois, em 1607, eles já faziam a catequese dos índios na Serra da İbiapaba.

Epidemias diversas assolaram freqüentemente o Ceará e motivaram o surgimento dos primeiros hospitais em sua capital.

A criação do Hospital de Jacarecanga, em instalações precárias, foi motivada pela epidemia da varíola de 1816. Para atender à demanda provocada por epidemias posteriores, ou à necessidade de por em quarentena os escravos recémchegados da África, a instituição foi ampliada diversas vezes. Com finalidade semelhante, e principalmente, para aten dervítimas da epidemia da febre amarela, que se iniciou em 1851, foi construido em 1855 o Lazareto da Lagoa Funda (12,p.118).

No ano de 1839 , quando ocorria uma das epidemias de malária, foi aventada a necessidade de se construir uma Santa Casa em Fortaleza, mas o plano não foi adiante. Maistarde, a construção foi iniciada e esteve sempre ameaçada de ceder lugar, ora ao Liceu a ser fundado, ora à Biblioteca Pública que não tinha sede. Em 1851, por ocasião de uma epidemia de febre amarela, ainda incabada, a construção foi aberta porque era necessário fazer atgo pelo saneamento da capital. Em 1857, o presidente da Província, Paes Barreto, cedeu algumas salas ao Liceu que permaneceu ali até 1861, quando, só então, ocorreu a inauguração formal da Santa Casa ${ }^{(12, \text { p. 119-122). }}$
O funcionamento da Santa Casa não era prioridade porque se destinava a atender os pobres, enquanto que of funcionamento do Liceu e da Biblioteca era exigido pela intelectualidade e pelasfamílias abastadas, que desejavamverseus filhos estudando em Fortaleza, e não mais se deslocando para Pemambuco e Bahia, como ocorria até então.

Em meio aos esforços para sanear a cidade de Fortaleza, em 1886 foi inaugurado o Asilo de Alienados São Vicente de Paulo ${ }^{5}$, onde se iniciou a prática psiquiátrica institucional no Ceará. Anexo à Santa Casa de Misericórdia, o asilo destinava-se à filantropia e tinha instalações precárias. A assistência era prestada por um médico que não era psiquiatra, enfermeiros práticos e pelas irmãs de caridade, a cargo de quem estava toda a responsabilidade da vida hospitalar. Até 1969, os médicos que ali prestavam assistência, o faziam gratuitamente ${ }^{(17)}$.

Pelo exposto, é possível admitir que no Ceará as freiras de caridade foram as precursoras da enfermagem psiquiátrica, a exemplo do que ocorreu no Rio de Janeiro em 1852, quando da inauguração do Hospício D. Pedro II (10) . As freiras comandavam as atividades na instituição e prova- velmente gozavam de certa autonomia, pelomenos no início, uma vez que ali trabalhava um único médico. A assistência era mais de caráter caritativo do que curativo, o que era condizente com o saber e a prática existentes na época.

A prática de enfermagem no asilo antecedeu em mais de meio século à instalação do ensino formale regular na profissão no Ceará.

O ensino de enfermagem foi implantado só em 1943, quando foi criada a Escola de Enfermagem São Vicente de Paulo. A idéia de criação de uma escola de enfermagem surgiu em 1942, quando o Patronato Nossa Senhora Auxiliadora, das freiras de caridade, promoveu cursos de Voluntários Socorristas de Defesa Passiva AntiÁerea, destinados às esposas de oficiais do Exército, Marinha e Aeronáutica (5).

Pelo nome dos cursos que motivaram a fundação da escola, conclui-se que a II Guerra Mundial teve influência em sua criaçăo. Outro fatormarcante na criação e funcionamento da escola, foi a influência das religiosas e do saber médico, pois de 1943 a 1973, a instituição teve apenas uma diretoria leiga e de 1943 a 1946 contou ao todo com 21 docentes, sendo 13 médicos, 1 padre, 6 enfermeiras religiosas e 1 enfermeira leiga. ${ }^{\bullet}$

\footnotetext{
5 Posteriormente o Asilo recebeu o nome de Hospital Psiquiátrico Sáo Vicente de Paulo e popularmente é conhecido como Asilo de Parangaba, uma referência ao bairro onde está localizado.

- No ano de 1968 a Escola foi dirigida por um colegiado composto de 3 freiras e4 enfermeiras leigas, onde se incluia Maria da Glória Ferreira Façanha, que assumiu direçấo sozinha no período de 1969 a 1971 (5, p.9e10).
} 
Só cinco anos após a implantação do ensino de enfermagem é que se implantou o ensino de medicina no Ceará.

Também estava claro, a imensa soma de benefícios que traria a futura Faculdade, tanto pelo aproveitamento das melhores vocações, como pela possibilidade oferecida às familias de melhores possibilidades económicas, de educar os seus filhos na própria terra de sua residência (12, p. 129).

Era evidente, portanto, a diferença social entre a escola de enfermagem e a de medicina. Enquanto as alunas de enfermagem se submetiam a trabalhar gratuitamente por um ano para custear os próprios estudos ${ }^{(5, \text { p. 78) }}$, os alunos de medicina pertenciamafamíliasdegrandesposses.

A década de 70 registra vários fatores diretamente relacionados com o ensino e a prática de enfermagem psiquiátrica no Ceará.

O ensino de enfermagem psiquiátrica nasceu no estado com a Escola de Enfermagem São Vicente de Paulo e esteve exclusivamente a seu cargo até meados da década de 70 . Até aquele momento, esse ensino, em sua parte teórica, estava a cargo de médicos. Durante essa década, o ensino da especialidade entrou em expansão com a criação dos Cursos de Enfermagem da Universidade Federal do Ceará, Universidade de Fortaleza e Universidade do Vale de Acaraú, esta última localizada na cidade de Sobral.

Foi na década de 70, também, que se iniciou o Curso de Residência do Hospital de Saúde Mental de Messejana para especializar psiquiatras, e que houve a primeira tentativa de ambulatorizar e interiorizar a assistência psiquiátrica no Ceará (2) .Estatentativa não foi muito bem sucedida, porque não chegou a afetar a assistência fundamentalmente farmacológica e até reforçou-a, na medida em que houve a distribuição, pela Central de Medicamentos (CEME), dos psicotrópicos prescritos aos que não tinham poder aquisitivo para comprá-los (20) . Entretanto, as enfermeiras que atuavam no setor, o faziam apenas com o preparo adquirido na graduação.

Só em 1980 é que o Ceará passou a contar com uma enfermeira psiquiátrica com título de especialista e outra com título de mestrado. Ligadas ao ensino em uma mesma universidade, elas começaram a organizar encontros, formais ou não, para discutir questões de interesse daqueles que atuam na especialidade. Os encontros de enfermeiros psiquiátricos do Ceará foram realiza- dos em 1983, 1985 e 1987, onde se discutiram questões que preocupavam o grupo como: o fato de o ensino prático de enfermagem psiquiátrica ocorrer basicamente dentro de hospitais, devido à inexistência de serviços ambulatoriais organizados de modo a reverter essa situação; aspectos como a qualificação do pessoal e falta de apoio administrativo referidos pelas enfermeiras eque, segundo elas, interferiam na qualidade da assistência prestada; inexistência de uma entidade que congregasseasenfermeiras psiquiátricas enquanto grupo profissional.

Mas a década de 80 foi marcada porintensas dificuldades financeiras nos hospitais psiquiátricos do Ceará, dificuldades estas retratadas pela imprensa local. Em 1984 um jornal com matéria intitulada "Govemador visita Asilo de Parangabae promete ajuda" relata a condição de penúria do primeiro hospital psiquiátrico fundado no Ceará: "O hospital São Vicente de Paulo já teria fechado, nåo fosse a ação filantrópica de um grupo de encontristas que auxilia com o que é possivel"(8). No mesmo ano, um outro hospital, também em Fortaleza, tem suas precárias condições de assistência à clientela e os baixos salários pagos aos funcionários denunciados pelo pessoal de enfermagem, que entra em greve ${ }^{(9)}$. Em 1990, a imprensa noticia novamente esse mesmo hospital, que foi interditado pelo setor de Vigilância Sanitária da Secretaria de Saúde do Ceará, após constatar a inexistência de condições mínimas para otratamento dos internados e o atraso de três meses no pagamento dos funcionários ${ }^{(11)}$.

Ainda na década de 80 (1987), em caráter temporário, o primeiro curso de especialização na área para enfermagem foi oferecido pela Universidade Estadual do Ceará. Das 15 pessoas que iniciaram o curso, 14 completaram os créditos, mas apenas 6 apresentaram monografia, exigência final para receber o título de especialista.

Fazendo um repasse dos acontecimentos descritos até aqui, é possível afirmarque mesmo no início da década de 90 , a prática de enfermagem psiquiátrica ainda não passou por transformações significativas.

\subsection{Assistência Psiquiátrica e Prática de Enfermagem Atuais.}

Embora a implantação de uma rede de serviços ambulatoriais psiquiátricos no Ceará tenha sido iniciada na década de 70 , isso não modificou 
essencialmente o perfil da assistência, ainda hoje centrada no hospital e de base fundamentalmente farmacológica. Em 1991, por ocasião da realização da pesquisa, estando em andamento a Reforma Sanitária e, mais especificamente, a implantação do Sistema Único de Saúde (SUS), mesmo as precárias equipes de saúde mental dos ambulatórios já não funcionavam. O que a implantação do SUS no Ceará provocou, com maior evidência na especialidade, pelo menos à época da pesquisa, foi o desmoronamento, talvez provisório, da frágil estrutura ambulatorial que existia. As razões para isso estão relacionadas aos diferentes salários pagos a técnico de mesmo nível nas diversas instituiçōes públicas que compõem o sistema, assim como às injunções políticas que seexacerbaram em todos os niveis, principalmente nos municipios, relacionadas às prioridades de aplicação das verbas vindas do nivel federal ${ }^{7}$. Portanto, as alternativas ambulatoriais não têm grande expressão no contexto da assistência psiquiátrica do Ceará.

Em 1991, o Ceará tinha 12 hospitais psiquiátricos totalizando 2113 leitos, sendo $1233 \mathrm{em}$ instituições privadas, 559 em instituições filantrópicas e 321 em instituições públicas. A partir do quadrol(Anexol), osleitos podem ser reagrupados também segundo sua localização, sendo 506 no interior e 1607 em Fortaleza.

Informações do IBGE revelam que em 1990, 0 Ceará contava com 6.653.346 habitantes, enquanto que Fortaleza tinha 1.758.334 habitantes $^{(6)}$. Estes dados, se cotejados com os anteriores, revelam que os leitos psiquiátricos estão concentrados na capital (1607), em detrimento do interior (506), o que não significa dizer que a assistência prestada em Fortaleza seja de boa qualidade, conforme a cobertura da imprensa relatada no tópico anterior.

Os hospitais psiquiátricos do Ceará, tanto públicos quanto privados, ou filantrópicos, têm características que os diferenciam mínima e superficialmente em relação aos seus pares. Quanto aos recursos que custeiam a assistência psiquiátrica, originam-se principalmente do poder públi- co, uma vez que quase todos os hospitais mantêm-se majoritariamente com os valores das diárias captadas de convênio com o SUS.

Pelos dados contidos nos Quadros I e II (Anexos (e II), pode-se verificarque, proporcionalmente, os hospitais públicos $(I, X I)$ empregam maior número de técnicos, sendo um total de 174 técnicos para 321 leitos, enquanto que os filantrópicos (IV, V, VII) têm 135 técnicos para 559 leitos, e os privados (II,III, VI, VIII, IX, XII) têm 252 técnicos para 1233 leitos.

Tomando ainda o Quadro II (Anexoll), e considerando especificamente o número de técnicos que trabalham em cada instituição, pode-se verificar que no topo do quadro e em sua base estão as categorias profissionais melhor representadas numericamente, presentes em todas as instituições, que sãoos psiquiatras e atendentes ${ }^{8}$. Entre essas duas categorias há um conjunto de outras (assistentes sociais, psicólogos, terapeutas ocupacionais etc.), sempre em número reduzido, cada uma delas ausente em pelo menos uma das instituições, constituindo única exceção, nesse caso, o grupo das enfermeiras que, mesmo em número reduzido, se fazem presentes em todas estas. Tais dados também apontam o fato de que o tratamento está centrado essencialmente no uso de psicotrópicos prescritos pelos psiquiatras e aplicados pelos atendentes. A enfermeira emerge, então, como o elemento que garante a execução e unidade do processo total de trabalho, tendo uma área de atuação que vai desde a coordenação do pessoal auxiliar de enfermagem, até o gerenciamento de aspectos genéricose díspares do ambiente onde o processo ocorre.

A clientela assistida nos serviços psiquiátricos do Ceará é composta majoritariamente porindivíduos de baixa renda, desempregados, sub-empregados, aposentados ou em processo de aposentadoria ${ }^{9}$. Muitos deles recorrem àqueles serviços, principalmente aos que oferecem apenas tratamento em regime de intemação, em busca de ganhos econômicos secundários, como a própria alimentação e o remédio a que têm direito, o auxílio pecuniário que receberão pela licença-

7 Tais informaçøes emergiram especialmente nas entrevistas de ns 30 e 38 , realizadas com emfermeiras.

- Outros estudos mostram que a polarizaçáo entre o número de médicos e atendentes ocorre também em outras especialidades. ${ }^{(13,16)}$.

- Tais informaçøes emergiram do conteúdo das entrevistas realizadas com o pessoal de enfermagem. Maiores detalhes sobre os ganhos secundários que a internaçáo psiquiátrica possibilita a desempregados, sub-empregados e candidatos à aposentadoria săo encontrados em MOREIRA (15). 
saúde ou o apressamento de um processo de aposentadoria. Tais situações são coerentes com o que seabordou no tópico 3.1. quanto à situação de Fortaleza, uma cidade que é centro de atração regional e cujo mercado de trabalho não absorve toda a população economicamente ativa, o que gera alta competitividade, aviltamentodossalários e desemprego.

Constatou-se entre oscomponentes da enfermagem entrevistados, que o valordos salários e o número de horas trabalhadas variam de uma instituição para outra, de um nível a outro da enfermagem emesmodentro de um mesmo nivel. Expressar os salários declarados pelos entrevistados em número de salários mínimos constituiu dificuldade significativa, e os valores encontrados devem ser entendidos como uma aproximação que está permeada de inexatidões relacionadas aos seguintes fatores: muitos dos entrevistados declaram seus salários de modo aproximado porque não sabiam ou não queriam expressar o valor exato que recebiam; de uma instituição para outra havia particularidades, como a existência, ou não, de gratificação portempo de serviço, a inclusão de valores relativos às horas-extras trabalhadas e ao serviço noturno, o pagamento, ou não, por insalubridade do serviço, ou por produtividade. Não desconhecendo estes aspectos, é possivel resumir a situação encontrada relativamente aos saláriospagos aos trabalhadores de enfermagem. Em 1991 , as instituições federais ${ }^{10}$ (XIII, XIV) pagavam melhores salários que as demais, e, entre estas, uma instituição filantrópica (VII) e uma privada pagavam os menores índices. Ovalordo salário pago a cada categoria da enfermagem variava menos entre os atendentes, quase sempre um salário mínimo. Já entre as enfermeiras, havia uma maior variação, entre 1,3 (VI) e 18,3 (XIV) salários mínimos. Eram os atendentes que trabaIhavam o maior número de horas, enquanto que recebiam os menores salários. Foi nesse grupo também que se encontrou o maior número de pessoas trabalhando em mais de um emprego, proporção que aumentava entre os homens.

Muitosdostrabalhadores de enfermagem revelaram estar trabalhando em psiquiatria porque foi a primeira oportunidade de emprego encontrada; outros se sentem discriminados entre seus pares que trabalham em outras especialidades, ou ma- nifestam a pretensão de sair em busca de outro trabalho, e se não o fazem é por temorao desemprego. Em consequência disso, dos salários baixos e das condições de trabalho precárias, há um fluxo migratório, especialmente das enfermeiras, indo do hospital psiquiátrico para outras especialidades.

Tomando parte dos dados levantados nos arquivos, constatou-se que, na instituição $I$, que é pública, no período de 1977 a março de 1991, foram contratadas 32 enfermeiras. Se incluidas as três que são contratadas como atendentes, o total chega a 35. No período, 18 delas se transferiram a pedido, para outros serviços públicos. Otempo de permanência delas na instituição / variou de 1 mês a 9 anose 10 meses. No mesmo levantamento, a instituição III caracteriza os serviços privados. Com um arquivo pouco organizado, só foi possivel realizar a consulta referente ao período de 1986 a janeiro de 1991, que revelou a passagem de 10 enfermeiras pela instituição, geralmente uma vez. Por ocasião da pesquisa, a instituição III tinha apenas uma enfermeira, contratada há 3 meses. O tempo de permanência delas ali variou de 1 mês a 3 ano's.

Portanto, no Ceará, a assistência psiquiátrica e a prática de enfermagem na especialidade não têm passado por transformações substanciais. Elas ocorrem essencialmente em Fortaleza e dentro de hospitais, pois o atendimento ambulatorial é inexpressivo numericamente. 0 tratamento está embasado no uso de psicofármacos prescritos pelo psiquiatra e a aplicação dos mesmos é feita pelos atendentes, sob a supervisão das enfermeiras.

\section{CONSIDERAÇÕES FINAIS}

Uma associação de fatores econômicos, sócio-políticos, regionais e culturais determinou 0 surgimento da prática de enfermagem psiquiátrica no Ceará. A interação dessa prática com a assistência psiquiátrica e com a sociedade cearense, confere-lhe o caráter e a especificidade que tem atualmente, só compreensíveis se considerados no conjunto, e não isoladamente.

A prática de enfermagem psiquiátrica surgiu no Ceará em 1886, no interior do Asilo de Alienados São Vicente de Paulo, em meio às medidas de 
saneamento da cidade de Fortaleza, para onde corriam levas de doentes e famintos, fugindo de secas e epidemias. Embora anterior ao ensino de medicina, o ensino de enfermagem e de enfermagem psiquiátrica já nasceram dependentes do saber médico. Só a partir de 1980, quando as primeiras enfermeiras se tornaram especialistas em psiquiatria, é que essa relação de dependência tendeu a se modificar.

Apesarde alguns avanços ocorridos nas déca- das de setenta e de oitenta, ainda na década de noventa, a prática de enfermagem psiquiátrica no Ceará não passou por mudanças significativas. Essa prática, como a assistência psiquiátrica que a inclui, continua centrada no interior de hospitais psiquiátricos localizados, em sua maioria, em Fortaleza. É uma prática embasada na aplicação de psicotrópicos prescritos pelos psiquiatras, aplicação queé feita pelos atendentes sob a supervisão das enfermeiras.

\begin{abstract}
A B S TR A C T: The study focuses on the practice of nursing assistance in psychiatric in Ceará. The data was collected by interviews and documents regarding history of nursing and of the assistance psychiatric in Ceará. On conclusion, the nursing practice is essentially supervision to the nursing team in delivering psychiatric medicine. The nursing practice has specific data to be considered on its study as whole: the relatinship between psychiatric assistance and society.
\end{abstract}

KEYWORDS: Psychiatric nursing - Mental health - History of nursing

\title{
REFERÊNCIAS BIBLIOGRÁFICAS
}

1- ALMEIDA, M.C.P. \& ROCHA, J.S.X. O saberda enferma gem e sua dimensão prática. 2. ed. Săo Paulo: Cortez, 1989

2 - FÉ, N. M. et al. Interiorizaçáo da psiquiatria no Ceará. Revista do Centro de Estudos Melaine Klein. Fortaleza, n. 1 , p. $55-58,1980$

3- FRAGA, M.N.O., DAMASCENO, R.N. \& BRAGA, V.A.B Prática de enfermagem na regiấo Nordeste. In: Congresso Brasileiro de Enfermagem, 37., Recife, 17-22, nov. 1986. Anais... Recife, Associaçăo Brasileira de Enfermagem, 1986, p. 131-136.

4 - $A$ prática de enfermagem psiquiátrica: subordinaçăo e resistência. Ribeirăo Preto, 1992. Tese (Doutorado). Escola de Enfermagem de Ribeiráo Preto. Universidade de Sáo Paulo, 1992.

5 - FRAZÃO, E.S. Trinta anos: Escola de Enfermagem Săo Vicente de Paulo. Fortaleza, 1973.

6 - FUNDAÇÃO IBGE: Censo demográfico 1991: resultados preliminares. Rio de Janeiro, 1991.

7 - GERMANO, R.M. Educação e ideologia de enfermagem no Brasil. Săo Paulo: Cortez, 1983.

8 - GOVERNADOR visita Asilo de Parangaba e promete ajuda. Tribuna do Ceará. Fortaleza, 24 set., 1984, p.5.

9 - GREVE para Casa de Saúde Santo António de Pádua. Diário do Nordeste. Fortaleza, 1. nov., 1984, p.9.

10 - GUSSI, M.A. Institucionalização da psiquiatria e do ensino de enfermagem no Brasil. Ribeiráo Preto, 1987. Dissertaçăo (Mestrado). Escola de Enfermagem de Ribeirăo Preto, Universidade de Såo Paulo, 1987.

11 - JAGUARIBE, E. Hospital psiquiátrico é interditado na Bela Vista. O Povo, Fortaleza, 10 abr., 1990, p. 11.
12 - LEAL, V.B. História da medicina no Ceará. Fortaleza: Instituto do Ceará, 1978.

13 - MÉDICI, A.C. Emprego em saúde na conjuntura recente. In: MÉDICI, A.C. (org.) Recursos humanos em saúde. Rio de Janeiro, ENSPIABRASCO, 1987, p.143-152, (Textos de apoio).

14 - MELO, C. Divisão social do trabalho e enfermagem. Săo Paulo: Cortez, 1986

15 - MOREIRA, D. Psiquiatria: controle e repressáo social. Petrópolis: Vozes, 1987.

16 - NOGUEIRA, R. P. A força de trabalho em saúde. In: MÉDICI, A.C. (org.) Recursos humanos em saúde. Rio de Janeiro. ENSPIABRASCO, 1987, p. 19-23, (Textos de apoio).

17 - PINTO, W. Misericórdia e repressáo. In: VELHO, P.M. Organizaçáo da psiquiatria no Brasil. Sáo Paulo: Sarvier,1981, p.83-98

18 - PIRES, D. Hegemonia médica na saúde e enfermagem. Sáo Paulo: Cortez, 1989.

19 - PONTES, W. Misericórdia e repressåo. In: VELHO, P. M. Organização da psiquiatria no Brasil. Sáo Paulo: Sarvier, 1981, p.83-98.

20 -SAMPAIO, J.J.C. Hospital psiquiátrico público no Brasil: a sobre vivência do asilo e outros destinos possíveis. Rio de Janeiro, $1988 . \quad$ Dissertaçáo (Mestrado). Instituto de Medicina Social, Universidade Estadual do Rio de Janeiro 1988.

21. SILVA, G. Enfermagem profissional: análise crítica. Sáo Paulo: Cortez, 1986.

Encaminhado para publicaçăo em 12/9/94

Aprovado para publicaçăo em 17/11/94 


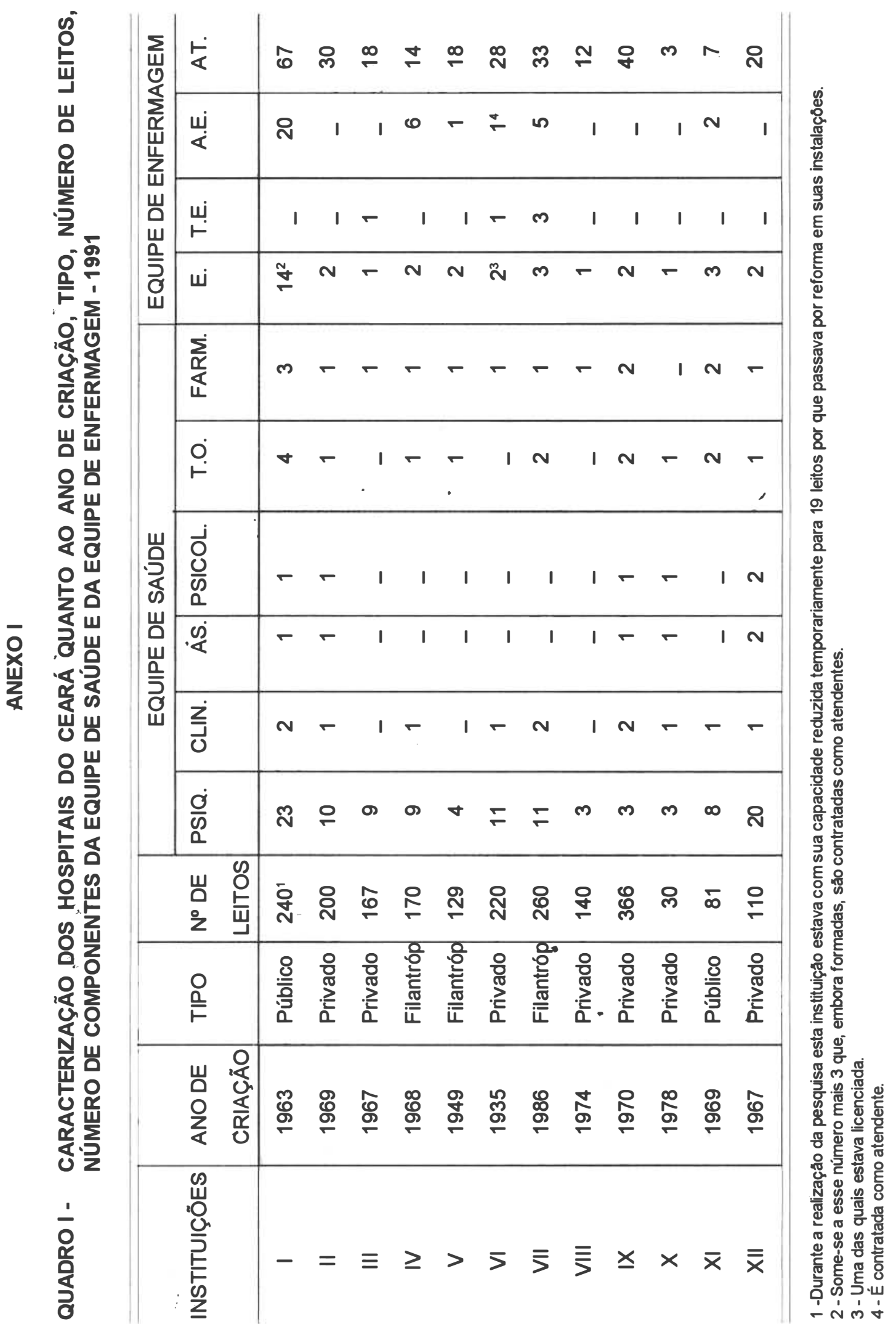


ANEXOII

QUADROII-DISTRIBUIÇÃO DOS TÉCNICOS NOS HOSPITAIS PSIQUIÁTRICOS DOCEARÁ, SEGUNDO O TIPO DE INSTITUIÇÃO-1991

\begin{tabular}{l|c|c|c|c}
\hline \hline \multirow{2}{*}{ TÉCNICOS } & \multicolumn{3}{|c|}{ HOSPITAIS } & TOTAL \\
\cline { 2 - 5 } Psiquiatras & PÚBLICOS & PRIVADOS & FILANTRÓPICOS & 116 \\
Clínicos & 31 & 59 & 24 & 12 \\
As. Sociais & 3 & 6 & 3 & 23 \\
Psicólogos & 12 & 7 & 4 & 4 \\
T. Ocupacionais & 1 & 3 & - & 15 \\
Farmacêuticos & 6 & 5 & 4 & 15 \\
Enfermeiros & 20 & 7 & 3 & 38 \\
Tec. Enfermagem & - & 11 & 7 & 5 \\
Aux. Enfermagem & 22 & 2 & 3 & 35 \\
Atendentes & 74 & 1 & 12 & 300 \\
TOTAL & 174 & 151 & 75 & 563 \\
\hline \hline
\end{tabular}

